UDC 629

\title{
Optimized Data Exchange Process between Design and Production Engineering
}

\author{
A. Kreis ${ }^{1)}$, M. Hirz ${ }^{1)}$ \\ ${ }^{1)}$ Institute of Automotive Engineering, Graz University of Technology (Graz, Republic of Austria) \\ (C) Белорусский национальный технический университет, 2020 \\ Belarusian National Technical University, 2020
}

\begin{abstract}
Growing vehicle variant diversity, legal requirements to reduce fleet $\mathrm{CO}_{2}$ emissions and innovations in the area of drive train technologies, coupled with the increasing pressure to cut costs, pose new challenges for parties in the automotive sector. An implementation of optimized development and production processes supports the effective handling of these challenges. One important aspect includes engineering efficiency improvement by optimizing the entire automotive bodywork development process and the involved data management. Research activities focus on the data exchange processes between design, simulation and production engineering within various CAx environments. This concerns constantly changing boundary conditions and requirements in the area of automotive body development, including but not limited to the introduction of new materials and material combinations and new types of joining technologies. From the viewpoint of an automotive engineering supplier, additional challenges caused by different customer-related development environments have to be considered. To overcome these challenges, various data exchange strategies between OEMs (Original Equipment Manufacturer), automotive suppliers and the use of different data management tools need to be investigated. In this context, the paper presents an approach of an optimized data exchange process of CAD-based data between different CAD (Computer-Aided Design) and CAM (Computer-Aided Manufacturing) environments that supports the entire body development, including data provision for manufacturing engineering. In addition, an optimization of data exchange processes saves development costs and improves the product quality.
\end{abstract}

Keywords: CAD-CAM process optimization, data exchange, automotive bodywork development, joining technology

For citation: Kreis A., Hirz M. (2020) Optimized Data Exchange Process between Design and Production Engineering. Science and Technique. 19 (1), 5-11. https://doi.org/10.21122/2227-1031-2020-19-1-5-11

\section{Оптимизированный процесс обмена данными в период между проектированием и производством}

\author{
А. Крайс ${ }^{1)}$, М. Хирц ${ }^{1)}$ \\ ${ }^{1)}$ Институт автомобилестроения, Грацкий технический университет (Грац, Австрийская Республика)
}

Реферат. Растущее разнообразие вариантов транспортных средств, законодательные требования по сокращению выбросов $\mathrm{CO}_{2}$ ими, инновации в области технологий трансмиссии в сочетании с усиливающимся давлением, направленным на сокращение расходов, ставят новые задачи перед участниками автомобильного сектора. Внедрение оптимизированных процессов разработки и производства поддерживает эффективное решение этих проблем.

\begin{tabular}{ll}
\hline Адрес для переписки & Address for correspondence \\
Крайс Александр & Kreis Alexander \\
Институт автомобилестроения, & Institute of Automotive Engineering, \\
Грацкий технический университет & Graz University of Technology \\
ул. Инффельдгассе, 11/2, & $11 / 2$ Inffeldgasse str., \\
8010, г. Грац, Австрийская Республика & 8010, Graz, Republic of Austria \\
Тел.: +43 677 623-195-44 & Tel.: +43 677 623-195-44 \\
alexander.kreis@tugraz.at & alexander.kreis@tugraz.at
\end{tabular}


Одним из важных аспектов является повышение эффективности инженерных решений за счет оптимизации всего процесса разработки кузова и управления данными. Исследовательская деятельность сосредоточена на процессах обмена данными на этапах проектирования, моделирования и производства в различных средах САх. Это касается постоянно меняющихся граничных условий и требований к разработке кузовов автомобилей, включая, помимо прочего, внедрение новых материалов и их комбинаций, а также новых технологий сборки. С точки зрения поставщика автомобильной техники, необходимо учитывать дополнительные факторы, вызванные различными средами проведения разработки, которые обусловлены потребностями пользователя. Чтобы решить эти проблемы, нужно изучить стратегии обмена данными между ОЕМ-производителями (ОЕМ - производитель оригинального оборудования) и поставщиками автомобилей с использованием различных инструментов. В статье представлен оптимизированный процесс обмена данными на основе CAD (компьютерное проектирование) между различными средами CAD и CAM (компьютерное производство), который поддерживает разработку всего кузова, включая предоставление необходимых показателей для производственного цикла. Кроме того, оптимизация процессов обмена данными позволяет уменьшить затраты на разработку и улучшить качество продукции.

Ключевые слова: оптимизация процесса компьютерного проектирования и производства, обмен данными, разработка автомобильного кузова, технология соединения

Для цитирования: Крайс, А. Оптимизированный процесс обмена данными в период между проектированием и производством / А. Крайс, М. Хирц // Наука и техника. 2020. Т. 19, № 1. С. 5-11. https://doi.org/10.21122/2227-1031-2020$19-1-5-11$

\section{Introduction}

In order to be able to counteract the progressive requirements in the automotive industry, the development processes must be continuously adapted. An increasingly important aspect for automobile manufacturers and suppliers is the production of climate-friendly vehicles. Besides others, this adaptation affects vehicle body development and manufacturing processes, including all materials used. For some time now, the so-called "multimaterial body design" has been used. Multimaterial body design is considered in such a way that a combination of several materials is used to create the BIW (Body-in-White) with the target to reduce weight $[1,2]$.

In addition to these material-heterogeneous vehicle bodies, pure steel bodies (e. g. for low-budget cars) and pure aluminum bodies (e. g. Audi A8 [3]) are also used, which leads to a wide range of different body architectures and associated material combinations. The mentioned change in the area of materials simultaneously leads to a change in the area of the required joining technologies $[4,5]$. While a pure steel body is mainly joined by spot welds and seam welds, other material combinations, in particular multi-material body design, use additional types of joining technologies [6].

Besides the application of different types of joining technologies, the various automobile manufacturers (OEMs - Original Equipment Manufacturer) also have their design-related preferences. Since a wide range of joining technologies is used, the automotive industry has to face new challenges in the areas of creating and managing joining technology data, as well as the exchange of these data and metadata between different disciplines and systems of computer-aided design and engineering disciplines (CA $x$ - Computer-Aided $x$, where $x$ serves as a placeholder).

This paper provides an approach of an optimized data exchange process of CAD-based (Computer-Aided Design) joining technology data between the engineering disciplines design and production (CAM - Computer-Aided Manufacturing). Furthermore, this article gives an overview of the state-of-the-art of body development processes and derives the increased requirements for the management of joining technology data.

\section{Problem statement}

Due to the mentioned changes in the field of automotive joining technology, there are no uniform processes for the exchange of joining technology data. In order to ensure an optimized data exchange process, the creation and administration of joining technology data (takes place in CAD environments), the data exchange process and the integration of data in target environments (e. g. CAE (Computer-Aided Engineering), CAM environment) must be considered.

Joining technology data contain all information required for the creation of joining technology elements in CAD environments. This includes all parameters and meta information that are required 
in other CAx environments and are, therefore, relevant for the data exchange. Each joining technology element is assigned a position vector $(x-, y$-, $z$-coordinates), the type of joining technology (e. g. spot welds, bolts, rivets, adhesives...), the parts to be connected (e. g. part number, part thickness, material...) and additional parameters (e. g. diameter, normal direction...). The additional parameters are usually tailored to the joining technology element (e. g. a diameter of the spot weld, the thickness of the weld seam, the normal direction for rivets, thread dimensions for screws...) [7]. In addition, joining technology data must be distinguished from geometry data in CAx environments. Geometry data contain information that describe the components (e. g. metal sheets) of the vehicle body (e. g. geometric dimensions, material, center of gravity...).

Due to the lack of standards (data formats, data structure, tools for creation, administration and distribution) in the area of joining technology data exchange, there is a gap in the data management processes. The existing gap in the management of joining technology data occurs in both, internal and external data exchange processes.

Internal data exchange processes cover the entire spectrum of data exchange in different CAx environments of one company (e. g. OEM, supplier...). On the other hand, external data exchange processes have to integrate at least two separate data management environments. While OEMs mainly concentrate on the internal data exchange process, suppliers have to consider both internal and external processes.

For automotive suppliers, it is of great importance to record and implement the occurring boundary conditions for external data exchange processes effectively. In order to clarify the requirements in data exchange, possible variants of development projects are subdivided into two types in view of the exchange of joining technology data.

The first type includes projects where all processes are handled internally in one company. This means that the creation of the joining technology data and the associated meta information take place completely in the internally CAD environment. The data exchange process from CAD to the target environment is carried out by using internal tools and methods. This results in a homogeneous situation (i. e. path of the data exchange process is always the same) with regard to data exchange. Finally, the joining technology data are integrated into the CAM target environment, so that further steps of manufacturing engineering are supported with the required information.

The second project type contains projects where the creation and administration of joining technology data take place partially or completely in an internal CAD environment, while the target environment is placed at another company externally. For this reason, one or more CAD environments (at least one is externally placed) participate in the entire data creation process. Since joining technology data can be created in more than one CAD environment, a heterogeneous data exchange process may occur in this case. This has an impact on the used data exchange file formats and data exchange strategies between the involved companies. Finally, the externally created joining technology data must be integrated into the targeted CAM environment.

In order to close the mentioned gap in joining technology-based data exchange, this paper provides an approach for an optimized data exchange of joining technology data for the different introduced use cases.

\section{Automotive body design}

As prior stated, the development of automotive bodies (BIW), including but not limited to the topics body architectures, crash-, strengths- and durability, materials and joining technologies, has changed over the last decades $[6,8]$. The change in this field is mainly driven by the issues of vehicle safety, weight management and cost reduction. Exemplary an aluminum vehicle body can save up to $40 \%$ in weight compared to a steel body, taking into account similar stiffness and strength values $[1,3]$.

To enable balanced optimization, the "multimaterial body design" approach has been around for some time now, as it enables weight savings, under consideration of material costs targets. The following Tab. 1 shows the distribution of materials used in exemplary modern car bodies (manufacturing year 2016) [9-11].

As can be seen in Tab. 1, modern vehicle bodies can be made of several materials. As a result, 
the field of joining technology has become much more complex in terms of the use of new types of joining technology and the number of joining technology elements applied (Tab. 2) [12].

Table 1

List of BIW materials of exemplary selected cars

\begin{tabular}{|l|c|c|c|}
\hline \multicolumn{1}{|c|}{ Material } & $\begin{array}{c}\text { Volvo V90 } \\
{[9]}\end{array}$ & $\begin{array}{c}\text { Peugeot 3008 } \\
{[10]}\end{array}$ & $\begin{array}{c}\text { Aston Martin } \\
\text { DB11 [11] }\end{array}$ \\
\hline Aluminum, \% & 6 & 5 & 53 \\
\hline Standard steel, \% & 27 & 27 & 5 \\
\hline $\begin{array}{l}\text { High strength } \\
\text { steel, \% }\end{array}$ & 67 & 62 & - \\
\hline Synthetics, \% & - & 65 & 42 \\
\hline
\end{tabular}

Table 2

List of used joining elements of exemplary selected cars

\begin{tabular}{|l|c|c|c|}
\hline $\begin{array}{c}\text { Type of joining } \\
\text { technology }\end{array}$ & $\begin{array}{c}\text { Volvo V90 } \\
{[9]}\end{array}$ & $\begin{array}{c}\text { Peugeot 3008 } \\
{[10]}\end{array}$ & $\begin{array}{c}\text { Aston Martin } \\
\text { DB11 [11] }\end{array}$ \\
\hline Spot welds, pcs. & 5250 & 4157 & - \\
\hline Rivets, pcs. & - & - & 1278 \\
\hline Clinches, pcs. & - & 14 & - \\
\hline Weld studs, pcs. & 247 & 83 & - \\
\hline Screws, pcs. & - & - & 52 \\
\hline Seam welds, m & 9.3 & 150.29 & - \\
\hline Adhesive lines, $\mathrm{m}$ & 79.4 & 20.22 & 152 \\
\hline
\end{tabular}

Due to the increasing complexity in body design, material definition, manufacturing processes and joining technologies, the complexity and data volume in the development of automotive bodies is on the rise. In this context, effective data management processes must be introduced to ensure that all information between the different CAx environments is processed and transferred effectively and without unwanted losses. These exchange processes of CAD-based joining technology data include the usual suitable data formats and tools applied to support the exchange processes $[13,14]$.

With the main focus on joining technology data, information can be exchanged either as native CAD data (e. g. CATIA [15], NX [16]), or by using neutral data exchange formats (e. g. list-based, XML-based [17], JT (Jupiter Tessellation) [18], STEP (Standard for the Exchange of Product Model Data) [19], etc.). Above all, interfaces have to be created for external data exchange (e. g. between OEM and supplier), so that the involved data exchange file formats can be integrated successfully.

\section{Approach}

As previously mentioned, it must be ensured that both internally and externally created CADbased joining technology data can be integrated into optimized data exchange processes (Fig. 1). Besides geometry-based data in native or neutral formats, joining technology data can also be available in neutral list-based formats (e. g. Excel file) or XML-based formats - depending on the agreed data exchange strategy of the involved companies. Because of the different input sources (file formats, file structure) available and the associated different data structuring, there is a high additional effort in the preparation of data for the CAM environment.

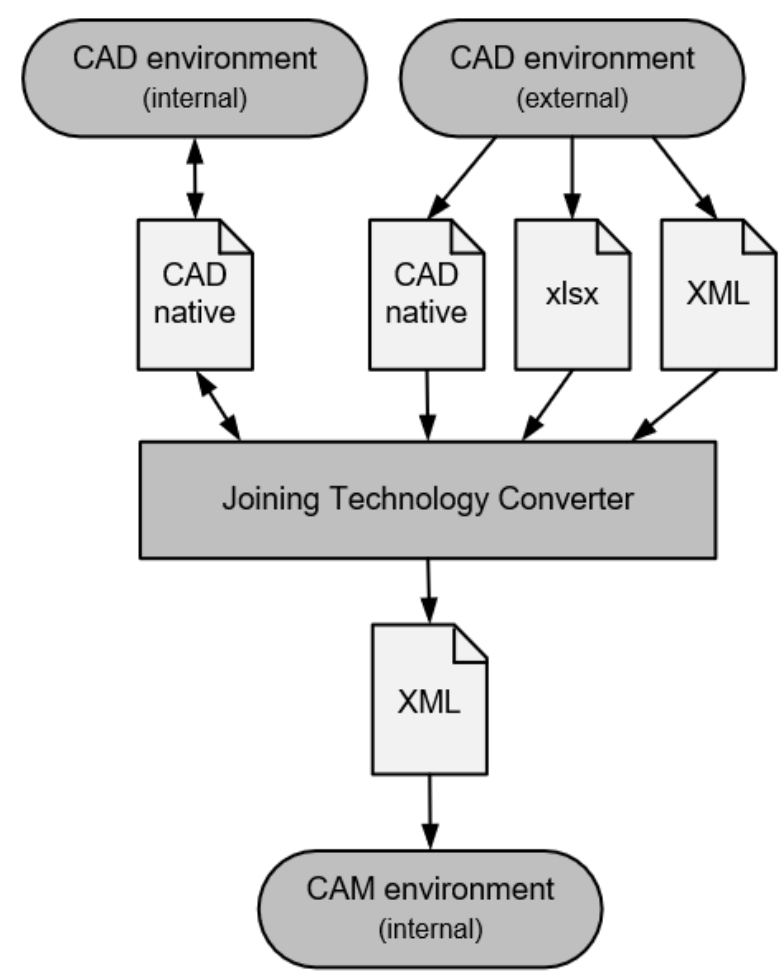

Fig. 1. Approach of the optimized data exchange process for joining technology data

This high expense results from the fact that the different input data must be prepared manually on a uniform data structure. Using a uniform data structure or a uniform data exchange format has the advantage that the data exchange process runs the same at all times. This can reduce 
the preparation time in the target environment significantly. Expenses that increase the preparation time include, among others, restructuring of input joining technology data and clearing and adjusting unneeded information and parameters.

A simple example of a joining technology element, a spot weld, is used to illustrate these expenses. When creating a spot weld in CAD environments, information such as geometrical depiction, coordinates, diameter, height, weight, normal direction vector and parts to be connected is created. The target environment (e. g. CAM) only needs the coordinates, diameter, normal direction vector and part to be connected. Since further information is not needed or even undesired (leads to larger simulation models), the data must be prepared for each joining technology element.

In the present approach, the common data format XML (Extensible Markup Language) is used in the optimized data exchange process. XML combines the advantages of lean design, simple integrability in different tools and systems of the target environment as well as simple editability (if necessary). A leaner design of the data to be exchanged results from the fact that unneeded information and parameters are filtered and thus not transferred during the exchange, which reduces the amount and size of exchanged data.

The approach requires the implementation of an interface, which converts the data from the source formats into the used data exchange format (XML) of joining technology data. This interface is designed in such a way that it is a tailor-made tool, named "Joining Technology Converter". This tool can collect, merge and convert both internally created data (CAD environment internal - CAD native) and externally created data (CAD environment external - CAD native, XML-based and list-based). Since neutral geometry-based exchange formats (e. g. JT, STEP...) are rarely used for joining technology data, they are not considered in the approach of the optimized data exchange process.

In case that some parts of the joining technology data are internally, and some parts are externally available (created), the tool "Joining Technology Converter" offers an additional function. In this function it is possible to integrate the originally externally created joining technology data (source file either CAD native, list-based or XML-based) into the internal CAD environment. Thus, the $3 D$-CAD model can be completed in addition to further processing of the joining technology data in an XML file. Due to the use of this function, the complete joining technology data are available both in the internal CAD and CAM environment.

\section{Application of the approach}

The application of the newly introduced approach of optimized data exchange for joining technology data is shown by means of an exemplary data exchange procedure, which can be assigned to real projects in the automotive industry. In this scenario, the CAD-based joining technology data are exchanged between an OEM and a Tier 1 supplier. Furthermore, parts of the joining technology data are created internally (CAD environment of the Tier 1 supplier). The production of the vehicle body takes place after the successful data exchange and after fulfilling all CAM-engineering - related tasks (e. g. space analyses, accessibility checks for tools to create joining elements, planning of optimized production processes, calculation of processing time for joining elements, creation of an optimized joining sequence...) at the supplier.

Fig. 2 shows the application of the approach of optimized data exchange process of joining technology data. As a leverage point it can be assumed that the entire geometry data (e. g. geometrical characteristics, dimensions of the sheets, center of gravity, material...) are provided in the internal CAD environment.

Parts of joining technology data have already been created by the OEM and are exchanged by using Excel files. By using the tool "Joining Technology Converter" the available data are further processed into two different data formats. Once the external joining technology data are converted into an XML file, it can be transferred to the CAM environment. A further conversion of the external joining technology data into a native CAD file is necessary so that the $3 D$-CAD model can be extended with the external joining technology data.

In the present exemplary project, the creation of the remaining CAD-based joining technology 
data takes place in the internal CAD environment of the automotive supplier. As soon as the completion of these joining technology data is finished, the conversion of these native data into a neutral XML file takes place by use of the tool "Joining Technology Converter".

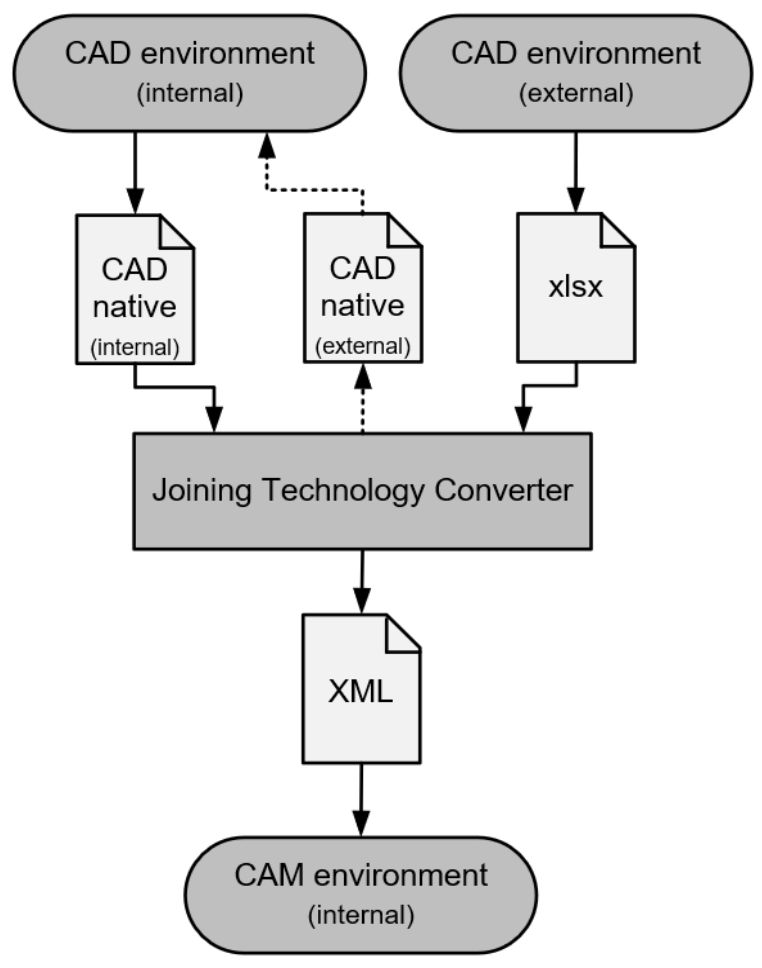

Fig. 2. Application of the approach of optimized data exchange for joining technology data in projects between different companies, e. g. OEM and supplier

Since the complete joining technology data are now available in XML file format, the data can be integrated into the CAM environment. As mentioned before, the joining technology data are prepared in such a way that they only need to be inserted into the corresponding processes. For this reason, no further data processing steps are necessary. Since the integration of geometry data takes place parallel to the integration of joining technology data, all necessary CAM - related engineering procedures can now be started effectively.

\section{CONCLUSIONS}

1. The current existing gaps in the data exchange of joining technology data is leading to increased efforts and expenses in the area of data management. These gaps are mainly caused by missing standards, as well as the high number of different exchange procedures applied. In this context, the present paper introduces an approach to close the gap in data exchange of joining technology data. Both internal and external data exchange possibilities as well as boundary conditions (e. g. data exchange file formats, data structure...) are considered.

2. In summary, it can be stated that the introduced approach of optimized data exchange processes of joining technology data can be applied to a large variety of projects. The optimized approach is flexibly designed so that it is possible to react quickly to new occurring requirements or boundary conditions (e. g. additional data exchange file formats, new types of joining technology, new parameters...).

3. Due to the implementation of process uniformity, the amount of information to be transferred is minimized. The reason for this is that the interface tool "Joining Technology Converter" only exchanges data required in the target environments. This leads to a shorter preparation time of data in the target environments and increases the efficiency in data management [20].

4. The presented optimized joining technology data exchange process provides a good starting point for a smart integration of knowledge-based design methods and design automation into car body development.

5. In practical investigations in automotive engineering projects, the application of the optimized data exchange process enabled a time reduction of up to $25 \%$ per CAM simulation loop. The optimization was achieved is mainly due to the fact that data conversion is used (tool "Joining Technology Converter") to reduce data exactly to the required data level. Thus, the preparation time of the joining technology data in the individual CAx environments can be massively reduced.

6. Since in typical car body development processes several optimization loops are performed, optimized data management enables considerable time and cost savings, which also supports earlier market launches of newly developed vehicles and their derivatives. 


\section{REFERENCES}

1. Niikura A. (2018) The Impact of the Application of Aluminum. ATZ Extra Issue - Motor Fan Special Edition Illustrated (Aluminum Technology 4).

2. Hirz M., Rossbacher P. (2016) Enhanced KnowledgeBased 3D-CAD Methods Supporting Automotive Bodyin-White Production Engineering. Management of Technology - Step to Sustainable Production, Porec, Croatia.

3. Autoevolution, Homepage of Autoevolution. https://www.auto evolution.com/news/audi-a8-the-car-body-of-the-year26659.html (Accessed 23 August 2019).

4. Pahl G., Beitz W., Feldhusen J., Grote K. H. (2007) Engineering Design: a Systematic Approach. Springer, Berlin, Germany.

5. Weber J. (2009) Automotive Development Processes Processes for Successful Customer Oriented Vehicle Development. Springer, Munich, Germany. https://doi.org/ 10.1007/978-3-642-01253-2.

6. Malen D. E. (2011) Fundamentals of Automobile Body Structure Design. SAE, Warrendale, PA, USA.

7. Kreis A., Hirz M., Stadler S., Salchner M., Rossbacher P. (2018) Convenient Connection Technology Data Model Supporting Optimized Information Exchange between CAx-Systems. Computer-Aided Design and Applications, 15 (5), 771-778. https://doi.org/10.1080/16864360.2018. 1441244.

8. Thum K., Hirz M., Mayr J. (2014) An Integrated Approach Supporting Design, Simulation, and Production Engineering of Connection Techniques in Automotive Body-in-White Development. Computer-Aided Design and Applications, 11 (4), 411-416. http://dx.doi.org/10. 1080/16864360.2014.881183.

9. Nedic S., D'Elia A., Palmquist N. (2016) The All-New Volvo V90 Car Body. EuroCarBody2016, Bad Nauheim, Germany.
10. Robert H., Scherrer J. M. (2016) New Peugeot 3008. EuroCarBody2016, Bad Nauheim, Germany.

11. Pugh-Jones Y., Richardson P., Walker F. (2016) Aston Martin DB11. EuroCarBody2016, Bad Nauheim, Germany.

12. Hachino M. (2018) Evolving Joining Technologies for Aluminum. ATZ Extra Issue - Motor Fan Special Edition Illustrated (Aluminum Technology 4).

13. Hirz M., Dietrich W., Gfrerrer A., Lang J. (2013) Integrated Computer-Aided Design in Automotive Development. Springer, Berlin, Germany. https://doi.org/10.1007/ 978-3-642-11940-8.

14. Kovacs G. L., Kochan D. (2013) Digital Product and Process Development Systems, IFIP TC 5 International Conference. Springer, Dresden, Germany, ISBN 978-3-64241328-5. https://doi.org/10.1007/978-3-642-41329-2.

15. Dassault Systems CATIA. Homepage of Dassault Systems. https://www.3ds.com/de/produkte-und-services/catia/ (Accessed 23 August 2019).

16. Siemens NX. Homepage of Siemens. https://www.plm. automation.siemens.com/global/de/products/nx/ (Accessed 23 August 2019).

17. Norm ISO 8879, Information Processing - Text and Office Systems - Standard Generalized Markup Language, 1986.

18. Norm ISO 14306, Industrial Automation Systems and Integration - JT File Format Specification for $3 D$ Visualization, 2017.

19. Norm ISO 10303, Industrial Automation Systems and Integration - Product Data Representation and Exchange, 2014.

20. Hirz M., Rossbacher P., Gavačová J. (2016) Future Trends in CAD - from the Perspective of Automotive Industry. Computer-Aided Design and Applications, 14 (6), 734-741. https://doi.org/10.1080/16864360.2017.1287675.

Received: 08.10.2019

Accepted: 10.12.2019 Published online: 31.01 .2020 